Article

\title{
The Influence of Eroded Blades on Wind Turbine Performance Using Numerical Simulations
}

\author{
Matthias Schramm ${ }^{1,2, *(1)}$, Hamid Rahimi ${ }^{1,2}$ (D) , Bernhard Stoevesandt ${ }^{1}$ (i) and Kim Tangager ${ }^{3}$ \\ 1 Fraunhofer Institute for Wind Energy and Energy System Technology, Küpkersweg 70, \\ Oldenburg 26129, Germany; bernhard.stoevesandt@iwes.fraunhofer.de \\ 2 ForWind, University of Oldenburg, Ammerländer Heerstr. 114-118, Oldenburg 26129, Germany; \\ hamid.rahimi@uni-oldenburg.de \\ 3 Blade Repair Solutions, Hedevej 25, Hadsund 9560, Denmark; kim.tangager@bladerepairsolutions.com \\ * Correspondence: matthias.schramm@uni-oldenburg.de; Tel.: +49-441-798-5015
}

Received: 23 August 2017; Accepted: 11 September 2017; Published: 16 September 2017

\begin{abstract}
During their operation, wind turbine blades are eroded due to rain and hail, or they are contaminated with insects. Since the relative inflow velocity is higher at the outer than at the inner part of the blades, erosion occurs mostly at the outer blade region. In order to prevent strong erosion, it is possible to install a leading edge protection, which can be applied to the blades after the initial installation, but changes the shape of the initial airfoil sections. It is unclear how this modification influences the aerodynamic performance of the turbine. Hence, it is investigated in this work. The NREL $5 \mathrm{MW}$ turbine is simulated with clean and eroded blades, which are compared to coated blades equipped with leading edge protection. Aerodynamic polars are generated by means of Computational Fluid Dynamics, and load calculations are conducted using the blade element momentum theory. The analysis in this work shows that, compared to clean rotor blades, the worse aerodynamic behaviour of strongly eroded blades can lead to power losses of $9 \%$. In contrast, coated blades only have a small impact on the turbine power of less than $1 \%$.
\end{abstract}

Keywords: erosion; rotor blades; airfoil simulation; Computational Fluid Dynamics; Blade Element Momentum theory

\section{Introduction}

Since wind turbines operate in the lower atmosphere, they are exposed to the local weather. Rain, hail or even insects lead to the erosion of rotor blades. Due to the higher rotational speed, this erosion mostly appears at the leading edges in the outer part of the blades. Although measurements of the aerodynamic effect of erosion on real operating wind turbines are rare, it is known that erosion leads to higher drag and lower lift, especially at angles of attack (AoAs) near the stall.

Dalili et al. [1] reviewed the effects of surface roughness due to insects or ice on wind turbine performance, but not much is said about the effect of leading edge erosion due to rain or hail. Corten and Veldkamp [2] showed within field experiments that increased roughness by insect contamination can lead to power losses of more than $25 \%$. It can be expected that strong erosion and resulting delamination lead to even higher power losses. Experiments with leading edge roughness on airfoils by Janiszewska et al. [3] showed a decrease in maximum lift of $25 \%$, whereas the minimum drag was increased by $60 \%$. The stall angle was shifted slightly to smaller AoA.

Sareen et al. [4] investigated the effect of erosion on airfoils experimentally with varying degrees of erosion, where the measurements were conducted at Reynolds numbers between $R e=1 \times 10^{6}$ and $R e=1.85 \times 10^{6}$ in a low-turbulence subsonic wind tunnel. In the case of heavy erosion, the maximum lift was decreased by $17 \%$ compared to the lift of the clean airfoil, and the drag was increased up to $500 \%$, although it should be noted that this increase did not refer to the minimum drag in the 
laminar drag bucket. The resulting polars of the experiments were used in numerical simulations of a 2.5 MW turbine based on blade element momentum theory (BEM), and they concluded that heavy erosion could lead to a loss in annual energy production (AEP) of approximately $25 \%$. Note that the simulations were done using the same level of erosion along the full blades, which is probably not the case for real turbines due to varying rotational speeds.

In order to avoid or prevent erosion, it is possible to use special leading edge protections. Weigel [5] investigated a protection system for helicopter blades, which are eroded by rain or sand. He showed that the protection used could reduce the effect of erosion. Still, helicopter blades are different from wind turbines due to different flow behaviour and rotor speeds. Additionally, the materials of helicopter blades and possible coatings are different from those of wind turbines.

In contrast, Giguere and Selig [6] experimentally investigated the effect of tapes on wind turbine airfoils. The wind tunnel measurements were conducted at low Reynolds numbers from $\operatorname{Re}=150,000$ to $\operatorname{Re}=500,000$ and airfoils which are not used on bigger turbines. The power losses due to the used tapes were less than $2 \%$, which is small compared to the losses with eroded airfoils. Still, it is not known how much a leading edge protection changes the wind turbine performance for modern multi-MW turbines compared to eroded airfoil shapes. This is the focus of this work, and in order to be able to reach the high Reynolds numbers of modern wind turbines, the investigation is done purely numerically.

Fernandez-Gamiz et al. [7] investigated the effect of microtabs and could show that wind turbine power can be increased by using these add-ons. They computed airfoil polars by means of Computational Fluid Dynamics (CFD) and used these polars in BEM computations to estimate the power output of a $5 \mathrm{MW}$ turbine. A similar approach is followed in this work.

Corsini et al. [8] report a numerical study of rain erosion on a $6 \mathrm{MW}$ turbine and compared standard and aerodynamically optimized blades with each other. They simulated erosion by a steady-state Euler-Lagrangian approach with droplet tracking using CFD, but they do not report any difference in total power or AEP between eroded and clean blades.

Thus, the following work shall give a numerical estimation of the expectable losses due to erosion, and shall compare the wind turbine performance to coated blades equipped with leading edge protection. The selected turbine is the NREL 5 MW research turbine [9], which is often used in comparative research studies $[10,11]$. It is a three-bladed horizontal axis upwind turbine with a rated power of $5 \mathrm{MW}$ at a wind speed of $11.4 \mathrm{~m} / \mathrm{s}$ and a rotational speed of $12.1 \mathrm{rpm}$. The airfoil in the outer region of the turbine is a slightly modified version of the NACA 64-618, called "NACA64_A17" in the NREL reports. Since the coordinates of this modified airfoil are not available for the authors, the NACA 64-618 was used instead.

After a validation of the numerical method, aerodynamic polars of clean, eroded, and coated airfoils were generated by means of CFD. Then, these polars were used in BEM calculations in order to estimate power and loads as well as the AEP for an exemplary site.

\section{Numerical Methods}

In this section, the numerical methods used in this work are described. The aerodynamic coefficients are computed by CFD, which is validated for the basic approaches. The generated polars are later used in turbine load calculations, which are based on the BEM theory.

\subsection{Simulation of Airfoil Aerodynamics}

The aerodynamic coefficients of the airfoils in this work were computed by means of CFD, where the steady-state Reynolds-averaged Navier-Stokes (RANS) equations were solved. The computations were conducted with OpenFOAM-2.3.0 [12], which is an open-source CFD code written in C++. The general validity of the code for wind turbine applications was shown by Herráez et al. [13].

Ferrer and Munduate [14] investigated roughness effects on an S814 airfoil by NREL and compared experiments to two-dimensional simulations. They showed that using the panel code XFoil $[15,16]$ with boundary layer tripping is not sufficient for modelling rough airfoils, and instead 
CFD is necessary, where rough wall functions and the $k-\omega$-SST model were used. Although it is often done, dirty conditions can be modelled only to some extent by tripped XFoil computations, because "roughness is a complicated phenomenon that cannot be reduced only to a change in the transition point location" [14]. Thus, as suggested, CFD is used in this work.

In order to close the RANS equations, the $k-\omega$-SST model was used [17], where a further equation for the intermittency $\gamma$ was added in order to consider transition from laminar to turbulent flow [18]. Two-dimensional hexahedral meshes ( $O$-structure) were used with 512 cells on the airfoil and 256 cells in the airfoil's normal direction, leading to approx. 130,000 cells in total. This mesh resolution was motivated by the mesh studies of the following Section 2.1.1. In order to completely resolve the wall boundary flow, a dimensionless wall distance of $y^{+}<1$ was used, and the radius of the domain was $80 \cdot c$, where $c$ is the chord length of the airfoil. Figure 1 shows an examplary mesh of the NACA 64-618 (complete domain and close-up view).
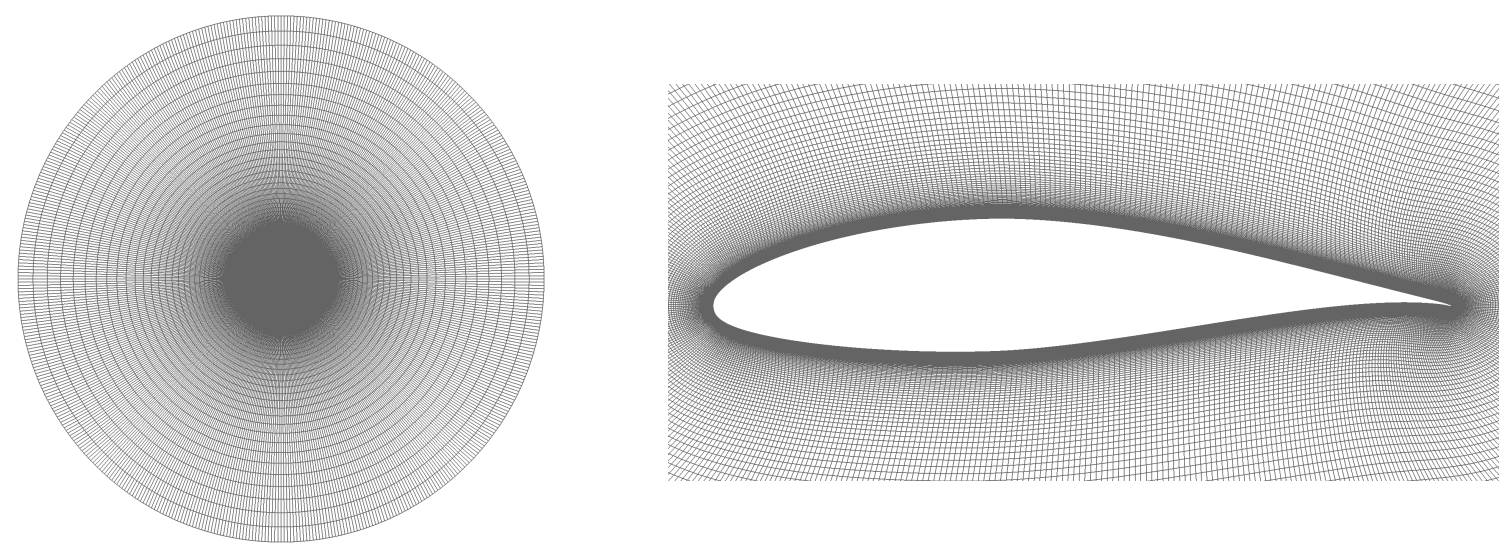

Figure 1. Complete domain and close-up view of the mesh for a NACA 64-618.

For simulating rough walls, wall functions were used, wherein the coefficients of the law of the wall were modified [19]. By the use of such wall functions, a higher dimensionless wall distance of $y^{+} \approx 30$ was used, and the number of cells in the radial direction was reduced to 192 .

In order to ensure that the numerical predictions of the following airfoil simulations can be used for the later load calculations of a wind turbine, the CFD is validated in this section. First a validation of a DU $96-\mathrm{W}-180$ at $R e=1.5 \times 10^{6}$ is shown for clean, rough, and strongly eroded configurations, then a validation of a clean NACA $64-618$ at $R e=9 \times 10^{6}$ is presented.

\subsubsection{Validation of DU $96-\mathrm{W}-180$ at $R e=1.5 \times 10^{6}$}

In experiments, surface roughness is sometimes modelled by boundary layer tripping, which is then simulated with a fixed transition location in numerical methods [20]. In fact, real roughness due to erosion leads to stronger effects than the ones of a tripped boundary layer [14], and thus a validation of numerical methods is done here against experiments having strong roughness.

Sareen et al. [4] experimentally investigated the effect of erosion with different strength on a DU 96-W-180 wind turbine airfoil at Reynolds number of $R e=1.5 \times 10^{6}$ in a low-turbulence subsonic wind tunnel. The clean airfoil is simulated here with a model for natural transition $\left(y^{+}<1\right)$. The strongest erosion in the work of Sareen et al. ("Type C, Stage 5") is compared here to simulations using rough wall functions $\left(y^{+} \approx 30\right)$ and a fully-turbulent flow model. Stronger erosion leads to delamination and a change in the leading edge shape, which is shown in Figure 2 on a real wind turbine blade. The turbine operates in an area with many insects (Australia), and the picture is taken approx. one year after installation. Turbines in other areas have a similar amount of erosion after a few years. 


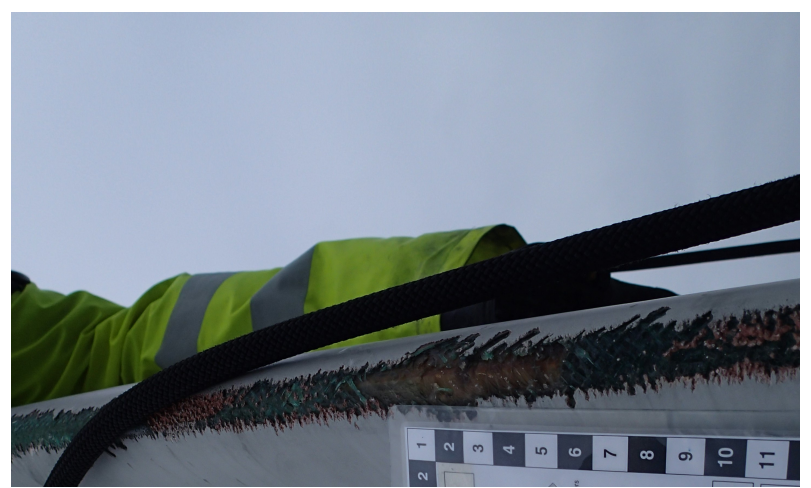

Figure 2. Erosion on a real rotor blade on a near-shore wind turbine after approx. one year of operation (courtesy of Blade Repair Solutions).

Such strong erosion can no longer be modelled by rough wall functions and thus a different leading edge shape needs to be simulated. The model used in this validation is shown in Figure 3 , which is simulated with a fully-turbulent flow model without transition, but resolved boundary layer $\left(y^{+}<1\right)$.

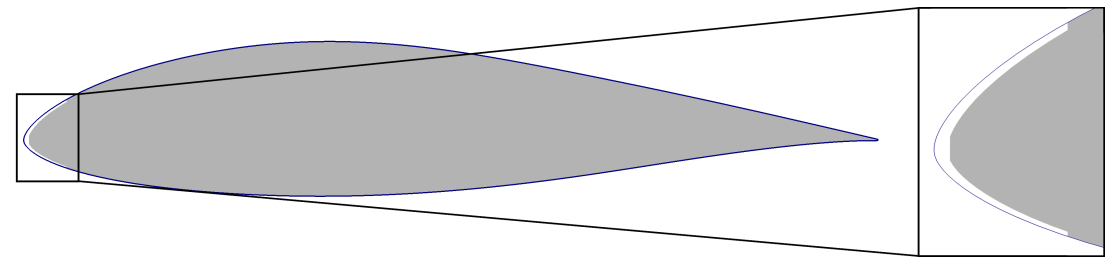

Figure 3. Sketch and close-up view of erosion modelled by a deformed leading edge as it is used in the two-dimensional CFD simulations (erosion model in grey and original DU 96-W-180 in blue).

Mesh studies were performed for all different levels of roughness, where in each study three different meshes with the same domain size and the same $y^{+}$-values were used. Going to a finer mesh, the number of cells are doubled in the radial direction and along the airfoil. In cases with rough wall functions, a higher dimensionless wall distance and accordingly less cells in the radial direction were used. The number of cells used in the mesh studies are shown in Table 1.

Table 1. Number of cells used in the mesh studies.

\begin{tabular}{cccc}
\hline & Cells Around Airfoil & $\begin{array}{c}\text { Cells in Radial Direction } \\
\text { for } \mathbf{y}^{+}<\mathbf{1}\end{array}$ & $\begin{array}{c}\text { Cells in Radial Direction } \\
\text { for } \mathbf{y}^{+} \approx \mathbf{3 0}\end{array}$ \\
\hline coarse meshes & 256 & 128 & 96 \\
medium meshes & 512 & 256 & 192 \\
fine meshes & 1024 & 512 & 384 \\
\hline
\end{tabular}

The results of the mesh study at an AoA of $4^{\circ}$ are shown in Table 2, where the relative differences $\delta_{\text {lift }}, \delta_{\text {drag }}$ are calculated based on the lift and drag coefficients resulting from the fine meshes. In most cases, a clear improvement of the medium mesh compared to the coarse mesh can be seen. Since the eroded airfoil is simulated with a different shape as shown in Figure 3, a higher resolution of the airfoil shape (i.e., more cells along the airfoil) leads to a different representation of the kink at the leading edge. This means that with different meshes, slightly different geometries are simulated, which shows the limitation of such a mesh study and explains the higher deviation of the drag coefficient for the eroded airfoil $\left(\delta_{\text {drag }}>2 \%\right.$ ). Nevertheless, the medium meshes are considered to deliver sufficiently converged results at moderate computing times. They were used for the following simulations. 
Table 2. Relative differences $\delta_{l i f t}, \delta_{\text {drag }}$ in (\%) of lift and drag coefficients compared to the coefficients resulting from the fine meshes (differences are presented as absolute values).

\begin{tabular}{ccccccc}
\hline & $\begin{array}{c}\text { Clean Airfoil } \\
\left(\mathbf{y}^{+}<\mathbf{1}\right)\end{array}$ & $\begin{array}{c}\text { Rough Airfoil } \\
\left(\mathbf{y}^{+} \approx \mathbf{3 0 )}\right.\end{array}$ & $\begin{array}{c}\text { Eroded Airfoil } \\
\left(\mathbf{y}^{+}<\mathbf{1}\right)\end{array}$ \\
\cline { 2 - 7 } & $\delta_{\text {lift }}$ & $\delta_{\text {drag }}$ & $\delta_{\text {lift }}$ & $\delta_{\text {drag }}$ & $\delta_{\text {lift }}$ & $\delta_{\text {drag }}$ \\
\hline coarse meshes & 0.074 & 6.1 & 0.96 & 1.3 & 4.2 & 18.0 \\
medium meshes & 0.31 & 0.74 & 0.13 & 0.28 & 0.063 & 2.2 \\
fine meshes & 0.0 & 0.0 & 0.0 & 0.0 & 0.0 & 0.0 \\
\hline
\end{tabular}

After the demonstration of the mesh independency, simulations were compared to experiments. Lift polars show the lift coefficient $c_{l}$ against the AoA. Drag polars show the lift coefficient $c_{l}$ against the drag coefficient $c_{d}$. The resulting lift and drag polars using different levels of roughness are shown in Figure 4.
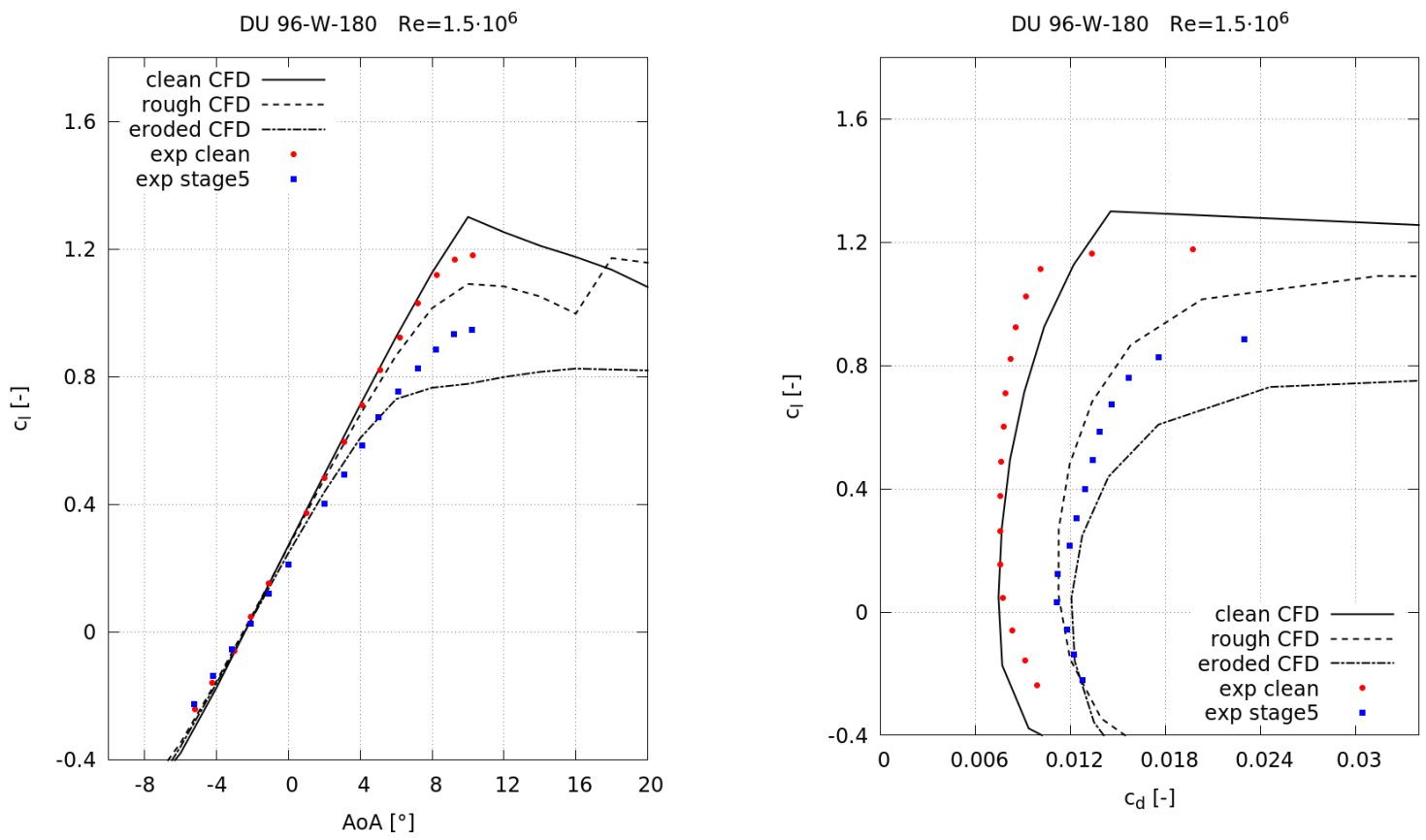

Figure 4. Validation of numerical results by Computational Fluid Dynamics (CFD) against wind tunnel measurements of a DU 96-W-180 at $R e=1.5 \times 10^{6}$ ("clean CFD" refers to resolved boundary layer with transition model, whereas "rough CFD" refers to the use of wall functions with fully-turbulent flow model and "eroded CFD" refers to a changed leading edge shape with resolved boundary layer and fully-turbulent flow model).

In general, the clean and rough simulations follow the trend of the experiments, but deviations can be seen in the stall, where the lift and drag coefficients are over-predicted by the CFD. This is a common problem of most turbulence models, and results from the two-dimensional steady simulations, but three-dimensional measurements of an unsteady flow. Furthermore, by the concept of rough wall functions, it is not possible to include the complete details of erosion, since the approximations in the modelling approach contain some limitations; for example, the airfoil shape is not changed and the simulated roughness is evenly distributed, which may not be the case in reality. Compared to clean and rough simulations, the deformed shape due to strong erosion showed an even stronger decrease in lift and increase in drag near the stall. This was not seen in the experiments, but there even the strongest erosion type ("Type C, Stage 5" [4]) did not lead to a deformation as it happens on real wind turbines (shown in Figure 2). With the presented methods of modelling clean, rough, and eroded 
airfoils, a broad range of surfaces can be simulated, and in order to investigate their influence on the turbine performance the numerical set-ups will be used in the later simulations as well.

\subsubsection{Validation of NACA $64-618$ at $R e=9 \times 10^{6}$}

The NACA $64-618$ is an airfoil with a relative thickness of $18 \%$, which was initially developed for use in the aviation industry, but can also be used in the outer region of wind turbines (e.g., the National Renewable Energy Laboratory (NREL) $5 \mathrm{MW}$ turbine in this work). The experimental results of the NACA 64-618 are taken from Timmer [21], who compared some work from Abbott et al. [22,23] with his own simulated results. The measurements were done in the Langley low-turbulence pressure wind tunnel (LTPT) at a Reynolds number of $R e=9 \times 10^{6}$ and the airfoil was measured in clean conditions.

Figure 5 shows the lift and drag polar of the numerical and experimental results. The general agreement between simulations and measurements is good, although some deviations can be seen. The numerical lift in the linear range is a little higher than in the measurements, and the drag is nearly constant instead of showing the laminar drag bucket of the experiments. Since the focus of this work is a comparative study, the validation results are considered to be good enough for the following investigations at high Reynolds numbers.
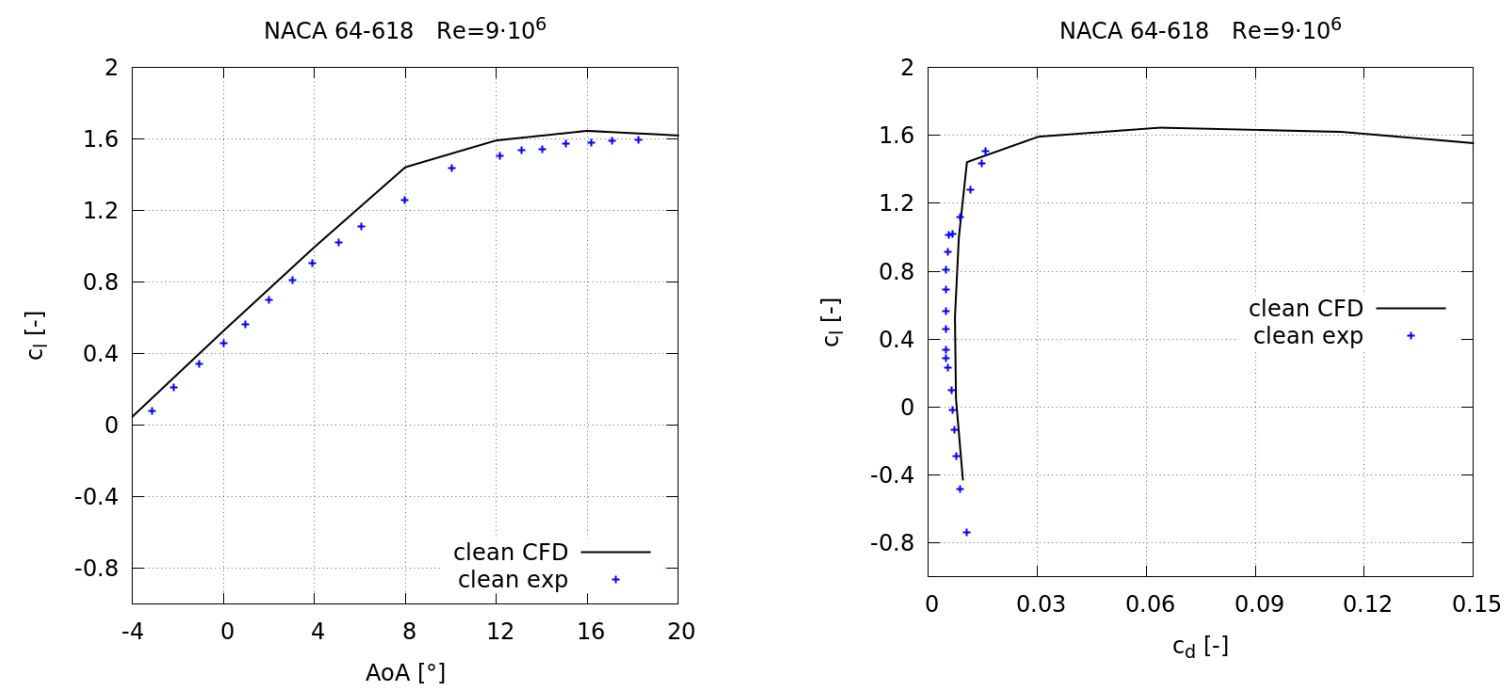

Figure 5. Validation of numerical results by CFD against wind tunnel measurements of a NACA 64-618 at $R e=9 \times 10^{6}$ ("clean CFD" refers to resolved boundary layer with transition model).

\subsection{Load Calculations}

The aerodynamic coefficients computed by means of CFD were used in turbine load calculations, which were performed by the aeroelastic BEM code FAST v8 [24]. FAST is developed by the National Renewable Energy Laboratory (NREL), and is established as a comprehensive aeroelastic framework, capable of predicting both the extreme and fatigue loads of two- or three-bladed horizontal-axis wind turbines. In this study, the effects of erosion and leading edge protection are investigated for the NREL 5 MW turbine [9], which is one of the certified tests in the FAST package.

Power, thrust force, and root bending moments are computed within FAST following the equations in the AeroDyn Theory Manual [25]. Vertical wind shear is calculated using a power-law, which is also part of the IEC Standards [26]. The tower is not modelled in order to isolate the effects of the different airfoil polars. An extrapolation for higher AoA is done by FAST with the method of Viterna [27], and the dynamic stall model of Beddoes and Leishman [28] is used. Air viscosity is selected to be $1.464 \times 10^{-5} \mathrm{~m}^{2} / \mathrm{s}$ with the air density of $1.225 \mathrm{~kg} / \mathrm{m}^{3}$. The pitch angles were kept constant between different cases in order to have a clearer performance comparison of the different airfoils. 


\section{Airfoil Polars with and without Leading Edge Protection}

After the validation of CFD methods, the airfoils with different leading edge shapes were simulated with the same computational set-up described in Section 2. Due to the different Reynolds numbers, the wall distance changed, but the dimensionless wall distance remained the same. The airfoils were simulated with clean and rough configurations, whereas a strongly eroded airfoil was simulated by a changed leading edge shape. The results were compared to a coated leading edge. Two different Reynolds numbers $\left(\operatorname{Re}=7.5 \times 10^{6}, R e=11.5 \times 10^{6}\right)$ were used due to the varying chord distribution and rotational speeds along the radius of the wind turbine blade. In order to limit the computational effort, the airfoil polars—which will be used in the following BEM simulations-were not generated for the complete range of $360^{\circ}$, because this is usually not required for normal operating turbines. Some cases (e.g., standstill) require aerodynamic coefficients at AoA of $90^{\circ}$, but this exceeds the interest of this work. Hence, the polars are generated only for AoA between $-24^{\circ}$ and $28^{\circ}$ with steps of $2^{\circ}$, which covers the range of interest in this work.

\subsection{Eroded Leading Edge}

As previously shown in Figure 2, strong erosion can delaminate and deform the leading edge of rotor blades. A simplified two-dimensional model of an eroded airfoil is shown in Figure 6, compared to the initial NACA 64-618.

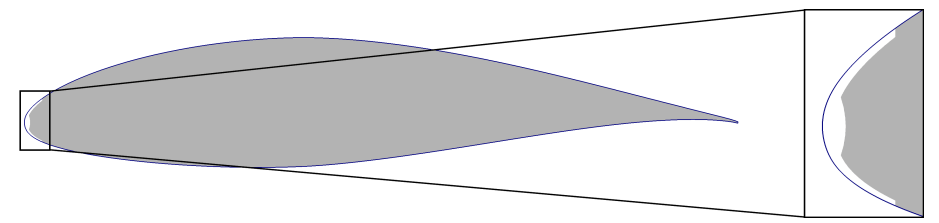

Figure 6. Sketch and close-up view of erosion modelled by a deformed leading edge as it is used in the two-dimensional CFD simulations (model for strong erosion in grey and original NACA 64-618 in blue).

The simulation results of such a shape are compared with the original airfoil under clean and rough conditions in Figure 7, where the lift and drag coefficients are shown against the AoA. Compared to the clean airfoil, the configuration with rough wall functions leads to a decrease in lift near the stall and a general increase in drag. When using the eroded shape, the lift is even further decreased. Additionally, the drag in the stall is further increased, although the minimum drag is smaller than at rough conditions, which could result from the particular leading edge shape modelled without additional rough wall function. In summary, rough and eroded airfoils clearly have a worse aerodynamic performance than the clean airfoil.

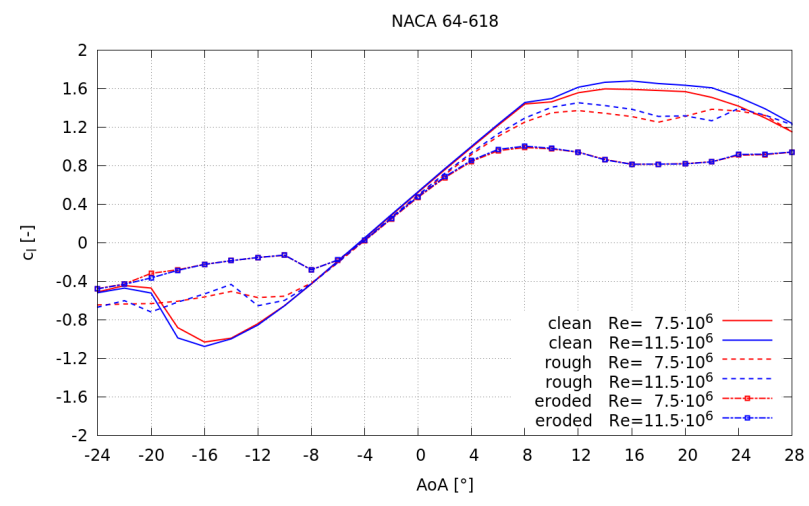

Figure 7. Cont. 


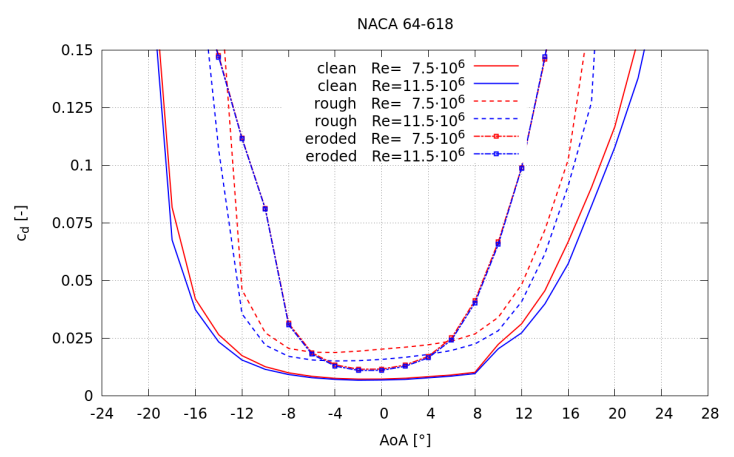

Figure 7. Numerical lift and drag coefficients of clean, rough, and eroded airfoils at $R e=7.5 \times 10^{6}$ and $R e=11.5 \times 10^{6}$ ("clean" refers to resolved boundary layer with transition model, whereas "rough" refers to the use of wall functions with fully-turbulent flow model and "eroded" refers to a changed leading edge shape with resolved boundary layer and fully-turbulent flow model).

\subsection{Leading Edge Protection}

In order to prevent erosion or in order to repair eroded wind turbine blades, it is possible to mount a special leading edge protection, which could also be applied on the blades after the initial installation. The coating can be applied on turbines without removing the blades, which reduces the costs compared to other techniques, since the shut-down time is shorter and the general maintenance effort is smaller.

Figure 8 shows the model of a leading edge protection on the NACA 64-618. The protection has a total length of $20 \%$ and ends at approx. $7.6 \%$ of the chord. At the leading edge center, it has a height of approx. $0.2 \%$ of the chord and approx. $0.1 \%$ at the ends of the protection. With these dimensions, the difference in shape may be in the order of the production tolerances of some rotor blades. Thus, it is expected that the coating has a small effect on the turbine performance.

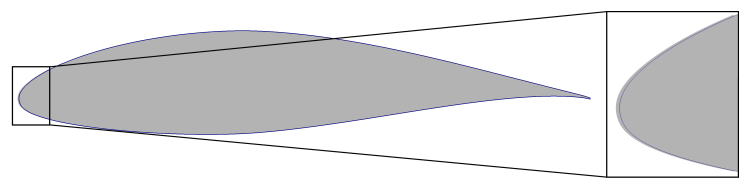

Figure 8. Sketch and close-up view of leading edge model with protection as it is used in the two-dimensional CFD simulations (model with protection in grey and original NACA 64-618 in blue).

The resulting lift and drag coefficients of the clean and coated airfoil are shown in Figure 9 against the AoA. Compared to the initial airfoil, the protection reduces the lift near the stall angles and the drag is increased at these, but also at smaller angles. The differences are on the order of approx. $8 \%$, but they are still clearly much smaller than in the rough or strongly eroded airfoils of the previous section.

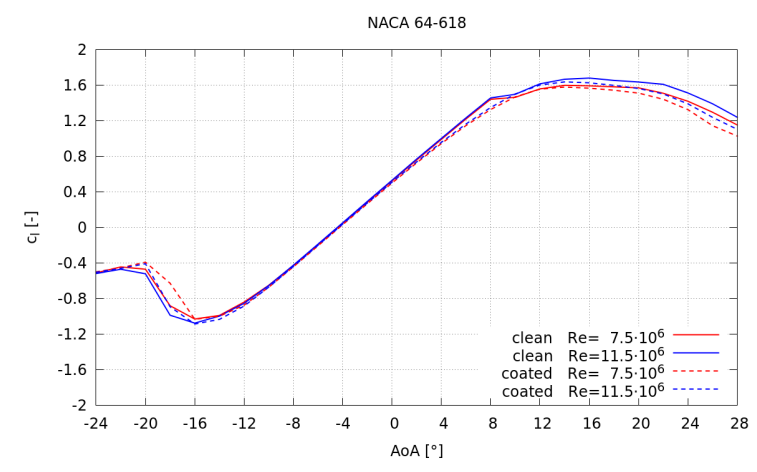

Figure 9. Cont. 


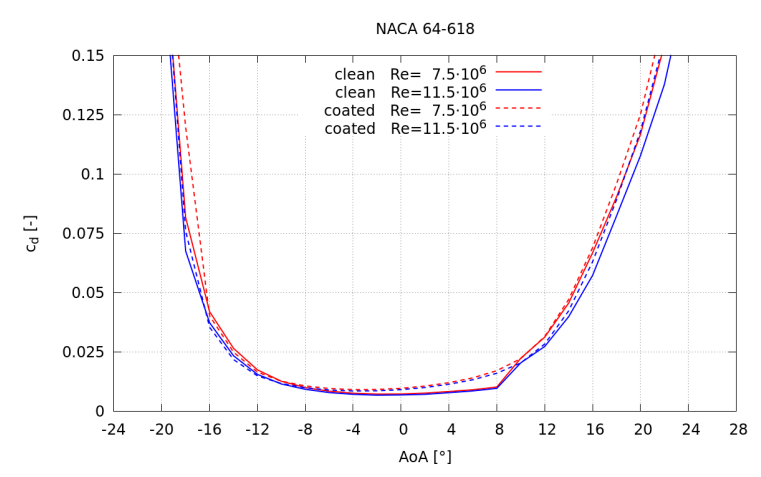

Figure 9. Numerical lift and drag coefficients $c_{l}, c_{d}$ of clean and coated airfoils at $R e=7.5 \times 10^{6}$ and $R e=11.5 \times 10^{6}$ ("clean" refers to resolved boundary layer with transition model, whereas "coated" refers to a changed leading edge shape with resolved boundary layer and fully-turbulent flow model).

\section{Simulation of Wind Turbines-Load Calculations}

In this section, the aerodynamic behaviour of a turbine using clean, rough, and eroded airfoils is compared to a turbine with leading edge protection. The load calculations were performed by the aeroelastic BEM code FAST v8 [24] as mentioned in Section 2. In this study, the effects of erosion and leading edge protection are investigated for the NREL 5 MW turbine [9], which is one of the certified tests in the FAST package. Table 3 lists the basic characteristics of this numerical reference turbine.

Table 3. Basic characteristics of the NREL 5 MW reference turbine [9].

\begin{tabular}{cc}
\hline Rated power & $5 \mathrm{MW}$ \\
Rotor diameter & $126 \mathrm{~m}$ \\
Axial induction & 0.25 \\
Cut-In, Rated Rotor Speed & $6.9 \mathrm{rpm}, 12.1 \mathrm{rpm}$ \\
Overhang, Shaft Tilt, Precone & $5 \mathrm{~m}, 5^{\circ}, 2.5^{\circ}$ \\
Tip speed & $80 \mathrm{~m} / \mathrm{s}$ \\
Hub height & $90 \mathrm{~m}$ \\
\hline
\end{tabular}

Most of the airfoil polars-namely, polars of the DU 40-A17, DU 35-A17, DU 30-A17, DU 25-A17, DU 21-A17 which are used in this contribution-are mainly from the FAST package [9]. Only the polars of the outer part of the blade from the NACA 64-618 were computed by means of CFD as explained in Section 3. Due to a varying chord distribution and rotational speed, the Reynolds number varies along the radius of the blade, and the airfoil polars were computed for two Reynolds numbers only; i.e., the minimum and maximum Reynolds number of the NACA 64-618 at rated conditions (inflow wind speed of $v_{\text {inflow }}=11.4 \mathrm{~m} / \mathrm{s}$ and rotational speed of $n=12.1 \mathrm{rpm}$ ). This leads to a Reynolds number of $R e=7.5 \times 10^{6}$ at a radial position of $61.63 \mathrm{~m}$ with a chord length of $1.42 \mathrm{~m}$ and to a Reynolds number of $R e=11.5 \times 10^{6}$ at a radial position of $44.55 \mathrm{~m}$ with a chord length of $3.01 \mathrm{~m}$. The polars by CFD computations were interpolated for other Reynolds numbers at intermediate sections.

\subsection{Aerodynamic Power, Thrust, and Root Bending Moments}

Figure 10 shows the aerodynamic power and the thrust curve for the rotor using the different airfoil polars from Section 3. Compared to the clean blade, the eroded airfoils led to a decrease in aerodynamic power for all wind velocities. In particular, above rated wind speed of $v_{\text {inflow }}=11.4 \mathrm{~m} / \mathrm{s}$, a power loss of $9 \%$ can be seen. A similar trend can be observed when comparing rough to clean blades. In contrast, the coated blade with leading edge protection reduces the power only slightly by approx. $1 \%$ compared to the clean blade. 
The eroded blade clearly led to lower thrust near the rated wind speed, whereas the rough blade only slightly decreased the thrust. The difference between clean and coated blades was negligibly small (below approx. 2\%). Hence, it can be concluded that, firstly, leading edge erosion will not lead to increase in thrust, and secondly the airfoil section with leading edge protection led to similar thrust as a clean blade.
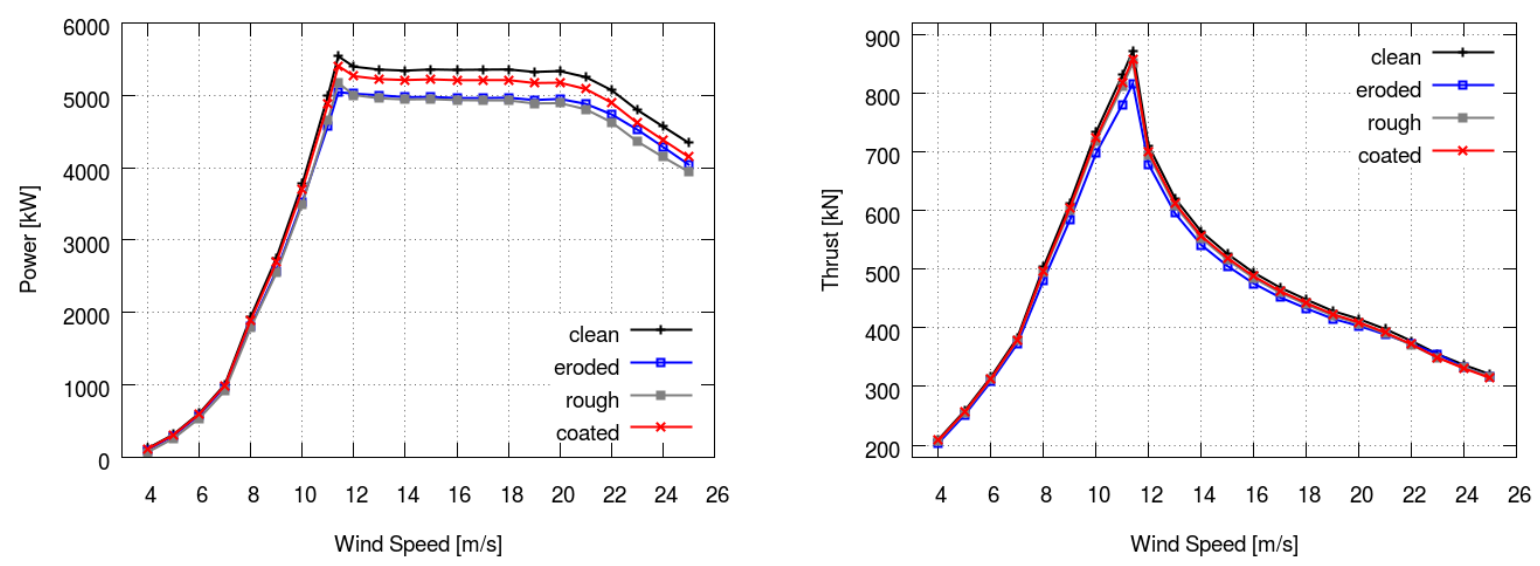

Figure 10. Power and thrust curve of the NREL $5 \mathrm{MW}$ turbine using different sets of polars for the NACA 64-618 airfoil.

For the rated case at $11.4 \mathrm{~m} / \mathrm{s}$, Table 4 lists a more detailed comparison of the aerodynamic power and rotor thrust for all sets of airfoil polars with regard to the clean blade, which is used as a reference in the comparison. It can be observed that the eroded and rough wind turbine blades could cause up to $9 \%$ loss in power production. Hence, the blade erosion has a significant effect on the wind turbine performance at rated conditions. In contrast, the use of a leading edge protection could limit the deviation, and the coated blade led to a power loss of less than $1 \%$ (at this wind speed), which may even be below the numerical errors.

The rotor thrust in Table 4 is less strongly affected by the blade erosion as the power output. This is related to the fact that surface roughness and blade erosion mainly have an effect on the drag. Since the lift polars do not differ significantly within the linear region, the thrust force is not as severely affected as the power.

Table 4. Comparison of the aerodynamic power and rotor thrust using different sets of polars at rated conditions (reference is the clean blade).

\begin{tabular}{lccccccc}
\hline & \multicolumn{3}{c}{} & & \multicolumn{3}{c}{ Difference in (\%) to Clean Blade } \\
\cline { 2 - 7 } & Clean & Eroded & Rough & Coated & Eroded & Rough & Coated \\
\hline power in $(\mathrm{kW})$ & 5540 & 5040 & 5170 & 5500 & -9.00 & -6.70 & -0.80 \\
thrust in $(\mathrm{kN})$ & 873 & 816 & 851 & 859 & -6.50 & -2.50 & -1.60 \\
\hline
\end{tabular}

Figure 11 shows the edgewise and flapwise root bending moments over the wind speed. At higher wind speeds close to the rated wind speed of $11.4 \mathrm{~m} / \mathrm{s}$ and above, the eroded and rough airfoil sections led to smaller edgewise moments compared to the clean blade. The differences between clean and coated blades were the smallest.

The flapwise root bending moments were generally similar to the thrust curves in Figure 10, and the eroded airfoil led to smaller moments. The rough airfoil section led to slightly smaller flapwise moments, and again, the differences between clean and coated blades were the smallest. 

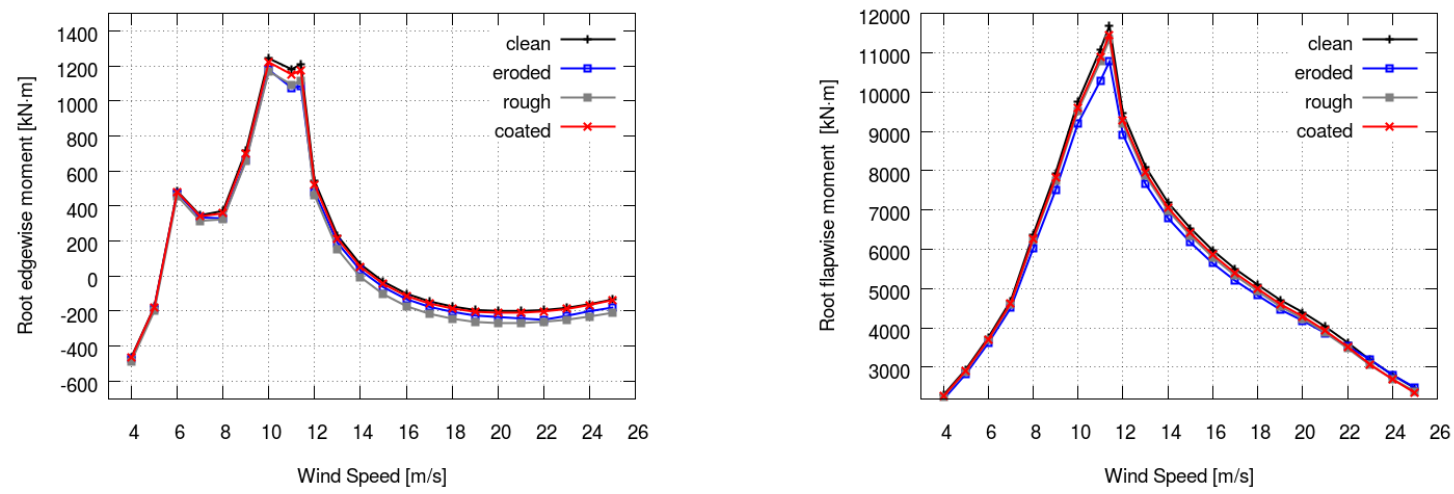

Figure 11. Edgewise and flapwise moments at the root for one blade of the NREL 5 MW turbine using different sets of polars for the NACA 64-618 airfoil.

Table 5 lists the results of blade root bending moments for rated conditions in a similar format as in Table 4. In terms of blade root bending moments, a trend similar to the aerodynamic thrust output can be observed. The loads at the blade root of the eroded and rough rotor blades show significant differences compared to the rotor blade equipped with erosion protection. Along with the decreased power output and the decreased rotor thrust, the root bending moments are also clearly reduced.

Table 5. Comparison of the edgewise and flapwise root bending moments using different sets of polars at rated conditions (reference is the clean blade).

\begin{tabular}{lcccccccc}
\hline & \multicolumn{3}{c}{} & & \multicolumn{3}{c}{ Difference in (\%) to Clean Blade } \\
\cline { 2 - 8 } & Clean & Eroded & Rough & Coated & Eroded & Rough & Coated \\
\hline edgewise moment in $(\mathrm{kNm})$ & 1210 & 1080 & 1120 & 1170 & -11.00 & -7.50 & -3.30 \\
flapwise moment in $(\mathrm{kNm})$ & 11,700 & 10,800 & 11,300 & 11,500 & -7.90 & -3.10 & -2.00 \\
\hline
\end{tabular}

It should be noted that the NREL $5 \mathrm{MW}$ turbine operates at AoA in the range of $4^{\circ}$ and $5^{\circ}$ at rated conditions. According to Figure 7, the deviations at this range between clean and eroded polars are not more than $15 \%$. However, it can be clearly seen that increasing the operational AoA higher than $6^{\circ}$ will lead to higher power losses and also more deviation in the loads, which may happen in turbines with a different design.

Figure 12 shows the aerodynamic power and thrust of the NREL 5 MW turbine at rated condition for different yaw angles from $0^{\circ}$ to $30^{\circ}$. As in the case under axial condition, the eroded and rough blades led to lower power and thrust compared to clean and coated blades. The differences seem to be constant when the yaw angle changes. For the clean and eroded blade, the corresponding differences stay within a range of approx. $9 \%$.
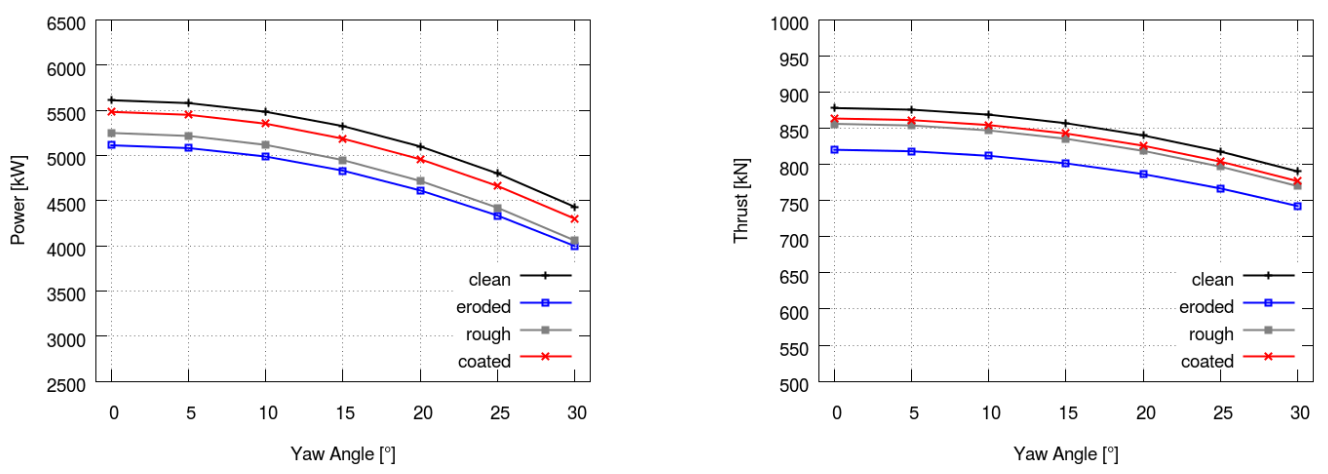

Figure 12. Rotor power and thrust against yaw angle of the NREL $5 \mathrm{MW}$ turbine at rated condition using different sets of polars for the NACA 64-618 airfoil. 


\subsection{Energy Production}

To judge the effect of the developed erosion protection, it is not sufficient to evaluate the power curve of a wind turbine only. Much more important in wind energy is the AEP of a wind turbine with coated blades in order to estimate the return on investment. To give an estimation of the effect on the AEP, the generated results from Section 4.1 were used to evaluate the AEP based on a Weibull distribution [29] for the wind velocities over one year. In this study, the wind speed distribution measured with a met mast at Risø was used [30]. Figure 13 illustrates the measured wind speed distribution of the site at Risø for different heights. The wind speed was measured for ten years at heights of $76 \mathrm{~m}$ and $117 \mathrm{~m}$. Since the hub height of the NREL $5 \mathrm{MW}$ wind turbine is $90 \mathrm{~m}$, the Weibull parameters were linearly interpolated in order to estimate the wind distribution for $90 \mathrm{~m}$. Hence, the resulting Weibull parameters are the shape parameter $\mathrm{k}=2.23$ and the scale parameter $\mathrm{A}=8.57 \mathrm{~m} / \mathrm{s}$, which represents the characteristic mean wind speed.

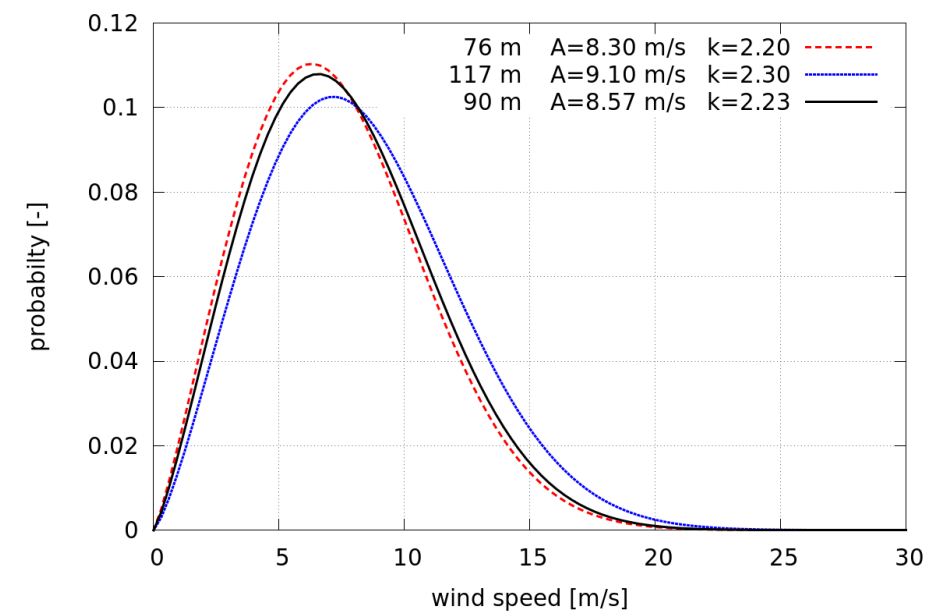

Figure 13. Wind speed distribution at two different heights of the Risø met mast [30] and interpolated wind speed distribution at $90 \mathrm{~m}$.

Using the Weibull distribution and the power curves from the previous section, the AEP can be easily calculated.

Table 6 shows the AEP for the NREL 5 MW reference turbine for the exemplary site using different sets of polars. For the sake of simplicity, it is assumed that the wind turbine has an availability of $100 \%$. It can be observed that the difference in aerodynamic power output, evaluated in Section 4.1, translates into a significant difference in the AEP for the different blades.

Table 6. Comparison of the annual energy production (AEP) using different blades.

\begin{tabular}{ccc}
\hline Blade Type & $\begin{array}{c}\text { AEP } \\
\text { (MWh/Year) }\end{array}$ & $\begin{array}{c}\text { Difference in AEP } \\
\mathbf{( \% )}\end{array}$ \\
\hline clean & 16,800 & 0 \\
eroded & 15,600 & -7.10 \\
rough & 15,400 & -8.30 \\
coated & 16,500 & -1.80 \\
\hline
\end{tabular}

Using rough or eroded blades resulted in a loss of approx. $8 \%$ in AEP, and although the lowest power at rated conditions was produced with the eroded blade (see Table 4), the AEP of the rough blade was the lowest in this comparison. This results from the slightly higher power output of the eroded blade at low and high wind speeds, which adds up to a slightly higher AEP compared to the rough blade. However, the wind turbine equipped with the coated blades using a leading edge protection had the lowest losses compared to the undamaged clean wind turbine blade. 
The losses can add up to a considerable amount of financial means if a lifetime of 20 years is considered for a wind turbine. Table 7 provides an overview of the loss in financial means for one year. Since the price per kWh depends strongly on the current situation on the energy market and/or existing contracts based on feed-in rates, in this study two different, exemplary prices are considered $(3 \mathrm{ct} / \mathrm{kWh}$ and $5 \mathrm{ct} / \mathrm{kWh})$.

Table 7. Comparison of the yearly loss of revenue using different blades for two exemplary energy prices (losses are compared to the yearly revenue of the clean turbine blades).

\begin{tabular}{ccc}
\hline & \multicolumn{2}{c}{ Yearly Loss of Revenue } \\
\cline { 2 - 3 } Blade Type & $\begin{array}{c}\text { with 3 ct/kWh } \\
\text { (EUR/Year) }\end{array}$ & $\begin{array}{c}\text { with } \mathbf{5} \mathbf{c t} / \mathbf{k W h} \\
\text { (EUR/Year) }\end{array}$ \\
\hline clean & 0 & 0 \\
eroded & $-37,500$ & $-62,500$ \\
rough & $-42,000$ & $-70,000$ \\
coated & -9000 & $-15,000$ \\
\hline
\end{tabular}

Significant differences can be observed, and the use of a leading edge protection seems to be beneficial compared to rough or eroded blades.

Still, this is a rough estimation, and strongly depends on various aspects such as site and installed turbine. A careful trade-off must be done between turbine repair and installation of a leading edge protection, where a loss of revenue appears as well.

\section{Conclusions}

In order to prevent wind turbine blades from strong erosion, it is proposed to use an erosion protection for the leading edge of rotor blades. In this work, the aerodynamic behaviour of a clean, rough and eroded blade of the NREL $5 \mathrm{MW}$ wind turbine was compared to a blade equipped with the proposed leading edge protection. Since mainly the outer parts of the blades are exposed to erosion due to the higher rotational velocity, the NACA 64-618 was selected as the airfoil of interest. To include the effect of erosion and roughness, new polars were generated using modified airfoil geometries and surface roughness by means of CFD. The aeroelastic simulation framework FAST was used to simulate the effect of different airfoil polars on the performance of a wind turbine. The aeroelastic load calculations showed that the eroded blades can lead to a drop in power output of up to $9 \%$. This directly translates into a loss in AEP of approx. $8 \%$, which reduces the financial income of a turbine due to erosion.

In contrast, it was shown that the blade equipped with leading edge protection performed similarly to the clean, undamaged blade. The power output was only slightly decreased and the money loss was much smaller than that of a turbine with eroded blades. Since the NREL 5 MW turbine operates at relatively low AoA (approx. $4^{\circ}$ ), an increase in the AoA due to yaw or pitch could lead to even stronger power losses. A significant increase in loads could not be observed in any of the investigated cases compared to the undamaged turbine with clean blades. This also means that the coated airfoil section did not increase the loads of the investigated turbine. From the presented results, it can be concluded that the proposed leading edge protection seems to be a good option when the blades are eroded. Still, it must be noted that several assumptions were made during this investigation (e.g., 2D numerical polars, met mast data from one site only, use of a research turbine). The results should be handled with care, and they can only give an indication of the phenomena in the real world. Moreover, the loss in power and money always depends on a particular site and turbine type.

Nevertheless, the results showed a considerable advantage of blades with leading edge protection over eroded shapes. From a purely technical point of view, it is proposed to use such protection devices, since the blades are often eroded after a fraction of their life time. Economically, the pay-off depends on the frequency and price of blade repair, and each operator should carefully calculate the 
trade-off between repair, leading edge protection, or further use of eroded blades. Economical studies could be done for a variety of sites and turbines. Besides, further investigations may be done either with more numerical details as well as wind tunnel measurements or on real operating wind turbines.

Acknowledgments: The authors also would like to thank Martin Dörenkämper (Fraunhofer IWES) for providing the information about the Weibull distribution at the exemplary site and Bastian Dose (Fraunhofer IWES) for support in evaluating the results.

Author Contributions: Matthias Schramm performed the CFD simulations and wrote the paper; Hamid Rahimi performed the BEM calculations as well as the calculations of the energy output and wrote the paper; Bernhard Stoevesandt supervised the work and analyzed the data; Kim Tangager contributed to the general interpretation of the results.

Conflicts of Interest: The authors declare no conflict of interest.

\section{Abbreviations}

The following abbreviations are used in this manuscript:

$\begin{array}{ll}\text { AEP } & \text { Annual Energy Production } \\ \text { AoA } & \text { Angle of Attack } \\ \text { BEM } & \text { Blade Element Momentum } \\ \text { CFD } & \text { Computational Fluid Dynamics } \\ \text { NREL } & \text { National Renewable Energy Laboratory } \\ \text { OpenFOAM } & \text { Open Field Operation And Manipulation } \\ \text { RANS } & \text { Reynolds-Averaged Navier-Stokes }\end{array}$

\section{References}

1. Dalili, N.; Edrisy, A.; Carriveau, R. A review of surface engineering issues critical to wind turbine performance. Renew. Sustain. Energy Rev. 2009, 13, 428-438.

2. Corten, G.P.; Veldkamp, H.F. Aerodynamics: Insects can halve wind-turbine power. Nat. Brief Commun. 2001, 412, 41-42.

3. Janiszewska, J.M.; Reuss Ramsay, R.; Hoffmann, M.J.; Gregorek, G.M. Effects of Grit Roughness and Pitch Oscillations on the S814 Airfoil; Technical Report; NREL/TP-442-8161; National Renewable Energy Laboratory: Golden, CO, USA, 1996.

4. Sareen, A.; Sapre, C.A.; Selig, M.S. Effects of leading edge erosion on wind turbine blade performance. Wind Energy 2014, 17, 1531-1542.

5. Weigel, W.D. Advanced Rotor Blade Erosion Protection System; Kaman Aerospace Corporation, USAATCOMTR95-D-8; Defense Technical Information Center: Bloomfield, CT, USA, 1996.

6. Giguere, P.; Selig, M.S. Aerodynamic Effects of Leading-edge Tape on Aerofoils at Low Reynolds Numbers. Wind Energy 1999, 2, 125-136.

7. Fernandez-Gamiz, U.; Zulueta, E.; Boyano, A.; Ramos-Hernanz, J.A.; Lopez-Guede, J.M. Microtab Design and Implementation on a 5 MW Wind Turbine. Appl. Sci. 2017, 7, 536.

8. Corsini, A.; Castorrini, A.; Morei, E.; Rispoli, F.; Sciulli, F.; Venturini, P. Modeling of Rain Drop Erosion in a Multi-MW Wind Turbine. In Proceedings of the ASME Turbo Expo 2015: Turbine Technical Conference and Exposition (GT2015), Montreal, Quebec, Canada, 15-19 June 2015.

9. Jonkman, J.; Butterfield, S.; Musial, W.; Scott, G. Definition of a 5-MW Reference Wind Turbine for Offshore System Development; Technical Report; National Laboratory of the U.S. Department of Energy, Office of Energy Efficiency and Renewable Energy; NREL: Wasington, DC, USA, 2009.

10. Fernandez-Gamiz, U.; Zulueta, E.; Boyano, A.; Ansoategui, I.; Uriarte, I. Five Megawatt Wind Turbine Power Output Improvements by Passive Flow Control Devices. Energies 2017, 10, 742

11. Jha, P.K.; Duque, E.P.N.; Bashioum, J.L.; Schmitz, S. Unraveling the Mysteries of Turbulence Transport in a Wind Farm. Energies 2015, 8, 6468-6496.

12. OpenCFD Ltd. OpenFOAM ${ }^{\circledR}$ _The Open Source Computational Fluid Dynamics (CFD) Toolbox. Available online: www.OpenFOAM.org (accessed on 14 September 2017). 
13. Herráez, I.; Stoevesandt, B.; Peinke, J. Insight into Rotational Effects on a Wind Turbine Blade Using Navier-Stokes Computations. Energies 2014, 7, 6798-6822.

14. Ferrer, E.; Munduate, X. CFD predictions of transition and distributed roughness over a wind turbine airfoil. In Proceedings of the AIAA 2009-269, 47th AIAA Aerospace Sciences Meeting Including the New Horizons Forum and Aerospace Exposition, Orlando, FL, USA, 5-8 January 2009.

15. Drela, M.; Giles, M.B. Viscous-Inviscid Analysis of Transonic and Low Reynolds Number Airfoils. AIAA J. 1986, 25, doi:10.2514/3.9789.

16. Drela, M. XFOIL: An Analysis and Design System for Low Reynolds Number Airfoils; Lecture Notes in English; Springer: Berlin, Germany, 1989.

17. Menter, F.; Esch, T. Elements of Industrial Heat Transfer Prediction. In Proceedings of the 16th Brazilian Congress of Mechanical Engineering (COBEM), Uberlandia, Brazil, 26-30 November 2001.

18. Menter, F.R.; Smirnov, P.E.; Liu, T.; Avancha, R. A One-Equation Local Correlation-Based Transition Model. Flow Turbul. Combust. 2015, 95, 583-619

19. Versteeg, H.K.; Malalasekera, W. An Introduction to Computational Fluid Dynamics-The Finite Volume Method; Longman Group Ltd.: London, UK, 1995.

20. Van Rooij, R.P.J.O.M.; Timmer, W.A. Roughness Sensitivity Considerations for Thick Rotor Blade Airfoils. In proceedings of the ASME 2003 Wind Energy Symposium, Reno, Nevada, USA, 6-9 January 2003.

21. Timmer, W.A. An overview of NACA 6-digit airfoil series characteristics with reference to airfoils for large wind turbine blades. In Proceedings of the 47th AIAA Aerospaces Sclences Meeting Including the New Horizons Forum and Aerospaces Exposition, Orlando, FL, USA, 5-8 January 2009.

22. Abbott, I.H.; von Doenhoff, A.E.; Stivers, L.S. Summary of Airfoil Data; NACA Report No. 824; NACA: Boston, MA, USA, 1945.

23. Abbott, I.H.; von Doenhoff, A.E. Theory of Wing Sections; Dover Publications, Inc.: New York, NY, USA, 1958.

24. Center, N.W.T. NWTC Information Portal (FAST). Available online: https:/ /nwtc.nrel.gov/FAST (accessed on 14 September 2017).

25. Moriaty, P.J.; Hansen, A.C. AeroDyn Theory Manual; Technical Report; National Laboratory of the U.S. Department of Energy, Office of Energy Efficiency and Renewable Energy; NREL: Washington, DC, USA, 2005.

26. Commission, I.E. Wind Turbines_Part 1: Design Requirements; Technical Report; International Electrotechnical Commission, IEC Standard; International Electrotechnical Commission: Geneva, Switzerland, 2005.

27. Viterna, L.A.; Corrigan, R.D. Fixed Pitch Rotor Performance of Large Horizontal Axis Wind Turbines; NASA: Lewis Research Center, Cleveland, OH, USA, 1982; pp. 69-85.

28. Leishman, J.G.; Beddoes, T. A Semi-Empirical Model for Dynamic Stall. J. Am. Helicopter Soc. 1989, 34, 3-17.

29. Fréchet, M. Sur la loi Rde probabilité de l'écart maximum. Annales de la Societe Polonaise de Mathematique: Cracovie, Poland, 1928.

30. Troen, I.; Petersen, E. European Wind Atlas; Technical Report; Risø National Laboratory: Roskilde, Denmark, 1989, ISBN 87-550-1482-8.

(C) 2017 by the authors. Licensee MDPI, Basel, Switzerland. This article is an open access article distributed under the terms and conditions of the Creative Commons Attribution (CC BY) license (http:// creativecommons.org/licenses/by/4.0/). 